\title{
Paradigmas da saúde e a (des)valorização do cuidado em enfermagem
}

Recebido em: 22/06/2012

Aceito em: 30/01/2013

\author{
Déborah Karollyne Ribeiro Ramos ${ }^{1}$ \\ Simone Karine da Costa Mesquita ${ }^{2}$ \\ Mayana Camila Barbosa Galvão ${ }^{3}$ \\ Bertha Cruz Enders ${ }^{4}$
}

Este artigo objetiva promover uma reflexão crítica acerca da influência paradigmática na (des)valorização do cuidado em enfermagem, abordando os aspectos teórico-conceituais que regem a prática desta categoria profissional. Trata-se de um ensaio teórico e analítico, apresentado na forma de exposição lógico-reflexiva, com ênfase na argumentação e interpretação pessoal. O cuidado de enfermagem sofre influência de paradigmas que permeiam os modelos de atenção à saúde no Brasil. Tal fato implica diretamente nas divergências evidenciadas na práxis dos profissionais da área e nos impulsiona a repensar o saber/fazer da profissão.

Descritores: Cuidados de Enfermagem, Atenção à Saúde, Enfermagem.

\section{Health paradigms and (de)valorization of the nursing care}

This article aims to promote a critical reflection on the paradigmatic influence on the (de)valorization of the nursing care, approaching the theoretical-conceptual aspects ruling the practice of this profession. This is a theoretical and analytical study, presented as a logical-reflexive exposition, focusing on the personal argumentation and interpretation. The nursing care is influenced by paradigms permeating the healthcare models in Brazil. Such fact directly implies the evidenced divergences in the praxis of the professionals in this area and makes us to have a second thought on the knowing/doing aspects of the profession.

Descriptors: Nursing Care, Healthcare, Nursing.

\section{Paradigmas de la salud y la (des)valorización del cuidado en enfermería}

Este artículo tiene el objetivo de promover una reflexión crítica sobre la influencia paradigmática en la (des)valorización del cuidado en enfermería, abordando los aspectos teóricos e conceptuales que rigen la práctica de esta categoría profesional. Se trata de un ensayo teórico y analítico, presentado en la forma de exposición lógica y reflexiva, con énfasis en la argumentación e interpretación personal. El cuidado de enfermería sufre influencia de paradigmas que permean los modelos de atención a la salud en Brasil. Tal hecho implica directamente en las divergencias evidenciadas en la praxis de los profesionales del área y nos impulsa a repensar el saber/hacer de la profesión.

Descriptores: Cuidados de Enfermería, Atención a la Salud, Enfermería.

\section{INTRODUÇÃO}

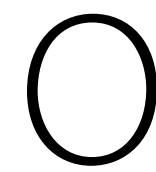
cuidado sempre esteve presente na história da humanidade, caracterizando a forma de viver e de se relacionar. Foi considerado, a priori, como uma atividade religiosa, onde as experiências eram passadas de geração a geração ${ }^{(1)}$. Atualmente, entende-se que o cuidado é uma característica intrínseca ao ser humano e caracterizada como uma atitude fundamental, na qual a pessoa sai de si e centra-se no outro com vigília e benevolência. Atitude que pode provocar, no cuidador, preocupação, inquietação e sentimento de responsabilidade pelas pessoas que necessitam dele ${ }^{(2)}$.

Na área da saúde, especialmente na enfermagem, o cuidado ganhou espaço e singularidade, sendo hoje conhecido como foco dominante e unificador da prática do enfermeiro ${ }^{(1)}$. Apesar de toda a importância atribuída ao cuidado, é perceptível em alguns profissionais a sua desvalorização, realidade que pode ser evidenciada através da ênfase dada às tecnologias duras, procedimentos meramente burocráticos e gerenciais. A referida desvalorização do cuidado pode estar relacionada, em muitos casos, às diversas influências culturais, religiosas, políticas, entre outras, e que revestem a prática de enfermagem de um caráter mecanicista, hospitalocêntrico, obediente e reducionista. Tais características são compatíveis com o paradigma cartesiano-newtoniano, que se tornou a base natural da ciência no período moderno(3).

$\mathrm{Na}$ pós-modernidade, a ideologia que passa a orientar as ciências e, consequentemente, a prática da enfermagem,

1 Enfermeira. Mestre em Enfermagem pela Universidade Federal do Rio Grande do Norte - UFRN. Docente do Curso de Graduação em Enfermagem da Faculdade de Ciências Médicas - FCM. Brasil. E-mail: deborah_kr@hotmail.com 2 Enfermeira. Mestre em Enfermagem pela UFRN. Brasil. 3 Enfermeira. Mestre em enfermagem pela UFRN. Brasil. 4 Enfermeira. PhD em Enfermagem. Professora Titular do Departamento de Enfermagem dos cursos de graduação e pós-graduação em Enfermagem/UFRN. Brasil. 
encontra-se em um período de transição, rompendo com a imagem mecanizada conferida ao paciente, e passando a valorizar o cuidado e a prática profissional reflexiva e com autonomia. Esse rompimento, ao mesmo tempo em que enseja uma crise no paradigma hegemônico, permite o início de uma revolução científica e, consequentemente, a construção de uma ideologia mais ampla na área da saúde ${ }^{(4)}$.

Ao introduzir o conceito de paradigma, Khun ${ }^{(6)}$ afirmou que este é o conjunto de elementos culturais, conhecimentos e códigos teóricos, técnicos ou metodológicos, compartilhados pelos membros de uma comunidade científica, o que a distingue da crença ou do senso comum. Quando um paradigma não consegue mais responder às necessidades de uma comunidade científica, este entra em crise, dando margem para o surgimento de outros paradigmas.

O surgimento de um paradigma que valoriza a integralidade permite o contato do profissional com uma nova forma de cuidar. O reconhecimento de diversas maneiras de visualizar e vivenciar o cuidado de enfermagem impulsiona-nos a repensar o modo de agir e fazer da profissão. Nesse sentido, o artigo tem como objetivo trazer uma reflexão sobre a influência paradigmática na (des)valorização do cuidado em enfermagem.

Buscamos lançar um olhar diferenciado sobre o exercício profissional do enfermeiro, de modo a refletir acerca da influência dos paradigmas prevalentes na saúde brasileira, na postura profissional de valorização ou desvalorização do cuidado em enfermagem. Essa reflexão oferece a oportunidade de uma melhor compreensão dos fatores associados ao exercício profissional do enfermeiro e pode resultar, a partir desse entendimento, em melhoria qualitativa da assistência de enfermagem prestada aos usuários dos serviços de saúde.

\section{METODOLOGIA}

Trata-se de um ensaio teórico e analítico, apresentado na forma de exposição lógico--reflexiva, com ênfase na argumentação e na interpretação pessoal. Este artigo corresponde a uma revisão narrativa da literatura científica, na qual aliamos pesquisas em bases de dados eletrônicas, em periódicos da área, em livros, em teses e em dissertações. Os resultados da reflexão foram agrupados em duas categorias: 1) “Resgatando os paradigmas que permeiam os modelos de atenção à saúde no Brasil"; 2) "A influência dos paradigmas na prática de enfermagem".

\section{Resgatando os paradigmas que permeiam os modelos de atenção à saúde no Brasil}

Para perceber a influência dos paradigmas na área da saúde no Brasil, é importante nos reportarmos aos contextos históricos do país. Durante o século XIX e início do século XX a situação da mortalidade em todo o mundo, inclusive no Brasil, era marcada pela predominância de doenças infecciosas. O conceito de saúde vigente na época correspondia à mera ausência de doença, não levando em consideração outros aspectos importantes para a sua manutenção. Tal posicionamento constituía uma âncora que permitia sustentar as práticas de saúde na atenção médica.

Nesse contexto, surge o paradigma que ficou conhecido como cartesianonewtoniano ou flexneriano, e que até hoje é fortemente atuante na nossa sociedade. Esse novo paradigma expressava--se por meio de um conjunto de elementos que coexistiam, se complementavam e se potenciavam $^{(7)}$, sendo eles: o mecanicismo, a unicausalidade, a tecnificação, o biologicismo, o individualismo, e principalmente o curativismo ${ }^{(7-8)}$. Sob este paradigma, a atenção é dirigida a sujeitos individuais em suas unidades morfológicas, impedindo a síntese entre o individual e o coletivo $^{(9)}$.

Denominado também de reducionismo, - paradigma cartesiano não tolera a interferência de valores humanos e religiosos, bem como qualquer variável relacionada à subjetividade. Divide o todo em partes e as estuda em separado, de forma isolada. Na área da saúde, esse modelo é chamado de biomédico e fez com que o corpo humano fosse comparado a uma máquina e o cuidado comparado a um conserto ${ }^{(10-11)}$.

A partir do final do século XIX, tem início um processo de rompimento com algumas concepções do mundo moderno, implementando-se a discussão de novas abordagens e formas de entendimento que hoje configuram a contemporaneidade. As transformações no panorama político e social do mundo e da situação de saúde, principalmente a falta de mudanças esperadas, põem em xeque as premissas e previsões de antigos modelos, em especial do clínico/biológico/flexneriano ${ }^{(3,12)}$.

Para atender às mudanças no perfil epidemiológico observadas no país, no transcorrer do século XIX, propõe-se a construção de um novo paradigma, o da produção social da saúde, orientado pelo conceito positivo de saúde, e tendo seus fundamentos calcados na teoria da produção social. Tal teoria permite romper com a divisão da realidade em setores e, dessa forma, além de responder por um estado de saúde em permanente transformação, rompe também com a ideia de um setor saúde, erigindo-a como produto social resultante de fatos econômicos, políticos, ideológicos e $\operatorname{cog}$ itivos ${ }^{(7)}$.

Para Mendes ${ }^{(7)}$, a reorientação dos sistemas de saúde na direção de se afirmar como "espaço da saúde", e não exclusivamente da atenção à doença, exige um processo de construção social de mudanças que se darão, concomitante e dialeticamente, na concepção do processo saúde-doença, no paradigma sanitário e na prática sanitária.

Esse novo paradigma apresenta um conceito ampliado de 
saúde, no qual ser saudável não pode ser apenas não estar doente. Deve significar também a possibilidade de atuar, de produzir a sua própria saúde, quer mediante cuidados tradicionalmente conhecidos, quer por ações que influenciem o seu meio - ações e políticas para a redução de desigualdades, educação, cooperação intersetorial, participação da sociedade civil nas decisões que afetam sua existência - ou, para usar uma expressão bem conhecida, no exercício da cidadania(8).

Esses dois paradigmas apresentam concepções filosóficas diferenciadas no que tange à saúde, à sociedade e à assistência, refletindo consequentemente na prática dos profissionais de saúde que seguem suas orientações. Mediante o exposto, partimos para a reflexão que envolve os paradigmas e a prática da enfermagem.

\section{A influência dos paradigmas na prática de enfermagem}

Ao longo da história, a enfermagem tem buscado construir um corpo de conhecimentos próprios para fundamentar seu exercício profissional. Guiada por concepções filosóficas contemporâneas no contexto histórico no qual está inserida, é uma ciência que procura atribuir significados aos fenômenos inerentes à profissão, variando seu foco e objeto de acordo com os paradigmas existentes no campo científico.

Partindo da compreensão de cada um dos paradigmas que permeiam os modelos de atenção à saúde no Brasil, e admitindo a importância das correntes filosóficas na formação do campo de conhecimento da enfermagem, refletimos acerca das implicações paradigmáticas na caracterização e desenvolvimento do processo de cuidar. Para tanto, focalizaremos o mesmo objeto - nesse caso, o cuidado de enfermagem, utilizando duas óticas diferentes: a Flexneriana e a da Produção Social da Saúde.

A prática orientada pela visão Flexneriana, ou biomédica, apresenta-se com tendência à quantificação do cuidado, evidenciado pela contabilização dos procedimentos nos serviços de saúde e o ganho por produtividade, reduzindo, assim, a complexidade do ser humano(13). Encontramos também a supervalorização de tecnologias duras, além da separação entre as visões social e coletiva do sujeito, o que parcela e fissura as ações de saúde e leva o enfermeiro a priorizar, em suas atividades cuidadoras, o espaço tissular ou celular portador da doença(5-14).

A prerrogativa herdada pelo paradigma cartesiano, que prega a necessidade de um saber médico que oriente o ser humano a ter saúde, alimenta a crença na supremacia do saber da enfermagem sobre o indivíduo, acarretando daí uma assistência autoritária e redutora da autonomia do usuário sobre si e seu tratamento(11). Essa orientação, que sofreu fortes influências do modo de produção capitalista, possui outro aspecto marcante, representado pela divisão (equivocada) e hierarquização do trabalho em saúde ${ }^{(13)}$. Nesse ponto, as ações laborativas do enfermeiro passam a ser dividas em duas categorias: as reservadas a quem detém o conhecimento científico, ou seja, "aquele que pensa", e as destinadas a quem executa o cuidado. Sendo assim, o enfermeiro profissional de nível superior, pensa, elabora e prescreve as ações de enfermagem e, ao profissional de nível médio, fica reservada a sua execução.

Tal forma de divisão do trabalho transmite ao técnico de enfermagem a falsa ideia de que ele não precisa ou não é capaz de conhecer a semiologia dos procedimentos que executa, a fisiologia do paciente ou a fisiopatologia da doença. Provavelmente por esse motivo, tal profissional acaba exercendo a atividade de maneira robotizada, onde apenas reproduz um conhecimento técnico previamente adquirido. Ele não toma consciência da importância de suas atitudes e não se dá conta da implicação daqueles procedimentos (em todos os seus contextos) para o desenvolvimento da saúde do usuário, situação que aponta para a negligência ou até mesmo para o desconhecimento da prática reflexiva, fundamental em todas as atividades profissionais.

Do outro lado, estão os profissionais de nível superior que, guiados por essa ideologia cartesiana, preterem o desenvolvimento de atividades práticas e de contato direto com o paciente, priorizando ações burocráticas e de gerenciamento e, assim, relegando a essência de sua profissão. Nessa perspectiva, evidenciamos a desvalorização do cuidado de enfermagem que, nesse cenário, prima por ações tecnicistas - uso de tecnologias duras -, em detrimento de ações que busquem o contato com a dimensão humana do indivíduo passando pela experiência de doença. Fato observado na prática e que confere ao cuidado um aspecto de descontinuidade.

Na outraface dessa dicotomia epistemológica, temoso paradigma da Produção Social da Saúde, que emerge com o interesse de trazer à luz das discussões a valorização das subjetividades, modificação na percepção do ser humano, revisão dos princípios éticos e busca dar voz ativa ao sujeito na vivência de seu processo saúde/doença(3).

Tais transformações ideológicas favoreceram o desenvolvimento de um cuidado diferenciado, marcado basicamente pelo ideal de integralidade na assistência e compreensão da necessidade do envolvimento com o outro, corresponsabilização e disponibilidade, além da preocupação com a ética, aspectos ecológicos e a harmonia entre os habitantes da Terra ${ }^{(15)}$. Em suma, o cuidado orientado pela visão da complexidade, do holismo ou da produção Social da Saúde, requer desvelo, solicitude, atenção e bom trato-enfim ter estima pela pessoa ${ }^{(3)}$. Em outras palavras, faz-se necessário uma boa relação enfermeiro--paciente para que possa se estabelecer a empatia necessária para a realização do cuidado.

Sendo assim, orientadas por esse paradigma, as ações de enfermagem adquirem uma maior dimensão social e priorizam (ou deveriam priorizar) o desenvolvimento das pessoas e dos grupos, reflexo do crédito conferido à influência das condições sócio- 
-econômicas no processo saúde/doença. O cuidado, por esse prisma, ganha maior representatividade, e deve atender às necessidades essenciais dos indivíduos, compreendendo ações de promoção, prevenção, cura e reabilitação, além de primar por tecnologias leves, estimular a autonomia, e ajudar o usuário a viver ${ }^{(14)}$.

Apesar de apresentados separadamente, esses paradigmas, bem como seus reflexos, podem ser evidenciados coexistindo na orientação da prática de enfermagem - seja ela profissional, social ou educativa - e constituindo motivo de paradoxos e conflitos ideológicos, que precipitam a dicotomia "teoria x prática" no que se refere às formas de produzir, executar e vivenciar o cuidado.

\section{CONSIDERAÇÕES FINAIS}

Neste estudo, buscamos apontar reflexões acerca da influência paradigmática na (des)valorização do cuidado em enfermagem, com intuito de causar uma inquietação e despertar estudantes e profissionais da saúde para a análise do cuidado em enfermagem. Incentivá-los a ver a realidade sob o olhar da complexidade, a ver àquilo que está camuflado.

Destarte, apresentamos, com abordagens nos paradigmas existentes, pontos relevantes inseridos na prática de enfermagem e que favorecem ou não a qualidade da assistência prestada pelos profissionais enfermeiros. A tendência observada já é evidenciada numa abordagem mais humana na enfermagem. Por outro lado, observa-se uma tendência de se privilegiar uma pluralidade de abordagens, o que equivale permitir diferentes maneiras de pensar e fazer em enfermagem.

Muitos profissionais de saúde dão pouca importância aos paradigmas que permeiam as práticas de enfermagem e suas influências. Na realidade, grande parte dos profissionais da área desconhece, ou conhece muito pouco, as bases teóricas e conceituais que envolvem o cuidado de enfermagem. Esse desconhecimento dificulta a compreensão e a reflexão crítica das suas próprias atitudes durante a realização das práticas assistenciais em enfermagem e, em última instância, comprometem o cumprimento de uma prática reflexiva.

É preciso estar sempre em busca de novos conhecimentos, com vistas a qualificar a assistência e partilhar essas informações com a equipe de trabalho, numa visão voltada para o ser humano. É fundamentalaprocuradealternativasparaaperfeiçoaraassistência ao cliente, fundamentada não apenas no conhecimento técnico-científico, mas também em valores pessoais, compreendendo o verdadeiro significado do cuidado humano.

$O$ processo reflexivo faz-nos repensar nossas posturas acadêmicas, profissionais e pessoais. É o ponto-chave para o sucesso da qualidade do processo de cuidar.

\section{Referências}

1. Waldow VR. Cuidar: expressão humanizadora da enfermagem. Petrópolis (RJ): Vozes; 2007.

2. Boff L. Saber cuidar: ética do humano - compaixão pela terra. Petrópolis (RJ): Vozes; 1999.

3. Terra MG, et al. O significado do cuidado no contexto do pensamento complexo: novas possibilidades para a enfermagem. Texto Contexto Enferm. 2006;15(esp):164-9.

4. Bueno FMG, Queiroz MS. O enfermeiro e a construção da autonomia profissional no processo de cuidar. Rev Bras Enferm. 2006;59(2):222-7.

5. Silva IJ, et al. Cuidado, autocuidado e cuidado de si: uma compreensão paradigmática para o cuidado de enfermagem. Rev EsC Enferm USP. 2009;43(3):697-703.

6. Kuhn TA. A estrutura das revoluções científicas. São Paulo: Perspectiva; 1970. 7. Mendes EV. Uma agenda para a saúde. 2a ed. São Paulo: Hucitec; 2006. 8. Santos JLF, Westphal MF. Práticas emergentes de um novo paradigma de saúde: o papel da universidade. Estud Av. 1999;13(35):71-88.
9. Coelho EAC, Fonseca RMGS. Pensando o cuidado na relação dialética entre sujeitos sociais. Rev Bras Enferm. 2005;58(2):214-7.

10. Capra F. O ponto de mutação: a ciência, a sociedade e a cultura emergente. $1^{\text {a }}$ ed. São Paulo: Cultrix; 1986.

11. Silva $A L$, Ciampone MHT. Um olhar paradigmático sobre a assistência de enfermagem: um caminhar para o cuidado complexo. Rev Esc Enferm USP. 2003;37(4):13-23.

12. Pain JS, Filho NA. Saúde coletiva: uma "nova saúde pública" ou campo aberto a novos paradigmas? Rev Saúde Pública. 1998;32(4):299-316.

13. Egry EY. Um olhar sobre as ciências da enfermagem: as vertentes analíticas das práticas assistenciais. Rev Esc Enferm USP. 2001;35(3):265-70.

14. Colliére MF. Promover a vida: da prática das mulheres de virtude aos cuidados de enfermagem. Lisboa: Sindicato dos Enfermeiros Portugueses; 1989.

15. Consoli GL, Hirdes A, Costa JSD. Saúde mental nos municípios do Alto Uruguai, RS, Brasil: um diagnóstico da reforma psiquiátrica. Ciênc Saúde Coletiva. 2009;14(1):117-28. 